\title{
Insulin Resistance is Immediately Reduced After Hemodialysis Sessions in Diabetic and Non- Diabetic Patients with End Stage Renal Disease
}

\author{
Abdel-Rahim AA ${ }^{1}$, Adam $\mathrm{AG}^{1}$, Zeitoun $\mathrm{MH}^{1 *}$, Abd El-Hamid $\mathrm{SE}^{1}$ and El-Gendi $\mathrm{WM}^{2}$ \\ ${ }^{1}$ Department of Internal medicine, Faculty of Medicine, Alexandria University, Egypt \\ ${ }^{2}$ Department of Clinical Pathology, Faculty of Medicine, Alexandria University, Egypt
}

*Corresponding author: Zeitoun MH, Department of Internal medicine, Faculty of Medicine, Alexandria University, Egypt

\begin{abstract}
Background: Insulin resistance in subjects with End Stage Renal Disease (ESRD) is a strong independent predictor of cardiovascular death. The immediate effect of hemodialysis Session on the state of insulin resistance in patients with ESRD is not very clear and requires further studies.

Methods: This self-control study was carried out at the Alexandria Main University Hospital; the study included 100 subjects with ESRD on regular hemodialysis (50 subjects with type 2 diabetes mellitus and 50 subjects without diabetes mellitus). Fasting plasma glucose, Fasting serum insulin, Homeostasis Model Assessment of Insulin Resistance (HOMA-IR), blood urea, serum creatinine and arterial bicarbonate were assessed before and after the hemodialysis sessions.

Results: The mean HOMA-IR was 4.58 in subjects with diabetes mellitus and 2.37 in subjects without diabetes mellitus. The levels decreased significantly to 1.28 in subject with diabetes mellitus $(\mathrm{P}<0.001)$ and decrease to 0.7 in subject without diabetes mellitus $(\mathrm{p}<0.001)$ after the hemodialysis session. There was a significant negative correlation between HOMA-IR and serum creatinine levels before or after the hemodialysis sessions.

Conclusion: Hemodialysis sessions may cause am immediate improvement in the insulin resistance state in patients with ESRD with or without history of T2DM; this could have some important cardiovascular and metabolic implications on this group of patients
\end{abstract}

Keywords: Insulin Resistance; End Stage Renal Disease; HOMA-IR

Abbreviations: BMI: Body Mass Index; ESRD: End Stage Renal Disease; HOMA-IR: Homeostasis Model Assessment of Insulin Resistance; T2DM: Type 2 Diabetes Mellitus

\section{Introduction}

Diabetic nephropathy is one of the most serious complications of diabetes mellitus; Diabetic kidney disease is responsible for about $40 \%$ of cases with ESRD [1-3]. Insulin resistance refers to decreased insulin ability to exert its physiological actions on different insulin sensitive tissues including the muscles, liver and the adipose tissue. Insulin resistance is not only related to the pathogenesis of type 2 diabetes mellitus (T2DM) but may also have a role in the development of chronic kidney disease [4]. In general, insulin resistance could be a pre receptor resistance, a receptor resistance or a post receptor resistance. Insulin resistance in chronic renal disease is mainly related to a post binding abnormality in insulin action [5-8]. Insulin resistance may lead to kidney damage through altering the renal hemodynamics by mechanisms such as activation of the sympathetic nervous system, sodium retention and decreased Na+, K+-ATPase activity [9]. HOMA-IR can be used as an alternative to the Hyperinsulinemic Euglycemic Glucose Clamp to estimate insulin resistance in patients with chronic kidney disease [10-13]. The effect of hemodialysis sessions on the state of insulin resistance in patients with ESRD was not clear. The aim of this study was to assess the immediate effect of hemodialysis session on insulin resistance in patients with ESRD. 


\section{Materials and Methods}

This self-control study included 100 adult patients with ESRD on regular hemodialysis (more than 6 months, three times per week, 4h session duration) selected from the Alexandria main university hospital. On the other hand, patients with morbid obesity (BMI $>40$ $\left.\mathrm{kg} / \mathrm{m}^{2}\right)$, Under-weight $\left(\mathrm{BMI}<18.5 \mathrm{~kg} / \mathrm{m}^{2}\right)$, type 1 diabetes mellitus or decompensated liver cirrhosis were excluded. The studied group was equally divided in to two subgroups; subgroup I (50 subjects with T2DM) and subgroup II (50 subjects without T2DM). The study was conducted in accordance with the Declaration of Helsinki and was approved by the Ethics Committee of Alexandria University, Egypt. Signed informed consent was obtained from each subject before any study-related activities [10]. Patients were asked to fast for 8 hours before HD session and to continue fasting till the end of the session. Blood urea, serum creatinine, arterial bicarbonate, fasting plasma glucose and fasting serum insulin were measured just before hemodialysis session and repeated immediately after hemodialysis session. Insulin resistance was calculated by HOMA IR using the formula: Fasting serum insulin $(\mu \mathrm{Uml}) \mathrm{x}$ fasting plasma glucose (mmol/L)/ 22.5 [10]. Data was analyzed by using student ' $\mathrm{t}$ ' test (paired and unpaired) and Pearson's correlation coefficient (r).

\section{Result}

\section{Descriptive Statistical Data of the Studied Patients}

The study included 100 patients with ESRD, the mean age of the studied patients was 49.7 years, the mean BMI was 25.2 and the mean duration for which the patients were on regular hemodialysis was 53 months (Table 1).

Table 1: Descriptive statistical data of the studied patients $(n=100$ patients).

\begin{tabular}{|c|c|c|c|c|}
\hline & Min. & Max. & Mean & S.D. \\
\hline Age (years) & 33.0 & 71.0 & 49.7 & 8.9 \\
\hline Weight (KG) & 48.0 & 87.0 & 69.2 & 8.9 \\
\hline BMI (Kg/m2) & 17.6 & 33.6 & 25.2 & 3.3 \\
\hline SBP (mmHg) & 110.0 & 175.0 & 136.5 & 16.2 \\
\hline DBP (mmHg) & 70.0 & 110.0 & 85.2 & 9.6 \\
\hline $\begin{array}{c}\text { Duration Of Hemodialysis } \\
\text { (months) }\end{array}$ & 47.0 & 62.0 & 53.0 & 4.1 \\
\hline
\end{tabular}

\section{Blood Urea}

The mean of blood urea levels significantly dropped from $101.2 \mathrm{mg} / \mathrm{dl}$ before hemodialysis sessions to $62.7 \mathrm{mg} / \mathrm{dl}$ after the hemodialysis sessions $(\mathrm{p}=0.013)$.

\section{Serum Creatinine}

The mean of serum creatinine levels significantly dropped from $10.0 \mathrm{mg} / \mathrm{dl}$ before hemodialysis sessions to $6.1 \mathrm{mg} / \mathrm{dl}$ after the hemodialysis sessions $(\mathrm{p}=0.011)$.

\section{Arterial Bicarbonate}

The mean of arterial bicarbonate levels significantly increased from $19.5 \mathrm{mmol} / \mathrm{l}$ before hemodialysis sessions to $24.5 \mathrm{mmol} / \mathrm{l}$ after the hemodialysis sessions $(\mathrm{p}=0.038)$.

\section{Fasting Plasma Glucose Level}

a) In subgroup I, the mean of fasting plasma glucose levels was $127.38 \mathrm{mg} / \mathrm{dl}$ before hemodialysis sessions and $96.62 \mathrm{mg} / \mathrm{dl}$ after the hemodialysis sessions $(\mathrm{p}=0.001<)$.

b) In subgroup II, the mean of fasting plasma glucose levels was $88.48 \mathrm{mg} / \mathrm{dl}$ before hemodialysis sessions and $78.96 \mathrm{mg} / \mathrm{dl}$ after the hemodialysis sessions $(\mathrm{p}=0.001<$ ).

\section{Fasting Serum Insulin}

Table 2: Fasting serum insulin level, fasting glucose level and HOMA IR before and after hemodialysis in the studied patients $(n=100$ patients).

\begin{tabular}{|c|c|c|c|}
\hline & Before HD & After HD & $\mathrm{P}$ \\
\hline \multicolumn{4}{|c|}{$\operatorname{Insulin}(\mu \mathrm{U} / \mathrm{ml})$} \\
\hline Range & $2.5-28.0$ & $1.0-13.3$ & \multirow{3}{*}{$0.001^{*}$} \\
\hline Mean & 14.2 & 4.6 & \\
\hline S.D. & 7.5 & 2.4 & \\
\hline \multicolumn{4}{|c|}{ Glucose (mg/dl) } \\
\hline Range & $74.0-210.0$ & $51.0-174.0$ & \multirow{3}{*}{$0.015^{*}$} \\
\hline Mean & 107.9 & 87.8 & \\
\hline S.D & 33.5 & 19.1 & \\
\hline \multicolumn{4}{|c|}{ HOMA IR } \\
\hline Range & $0.6-16.3$ & $0.2-3.8$ & \multirow{3}{*}{$0.0074^{*}$} \\
\hline Mean & 3.5 & 1 & \\
\hline S.D & 2.7 & 0.6 & \\
\hline
\end{tabular}

a) In the 100 studied patients, the mean of fasting serum insulin levels significantly dropped ( $\mathrm{p}=0.001$ ) from $14.2 \mu \mathrm{U} / \mathrm{ml}$ before hemodialysis sessions to $4.6 \mu \mathrm{U} / \mathrm{ml}$ just after the hemodialysis sessions (Table 2).

b) In the subgroup I, the mean of fasting serum insulin levels significantly dropped $(\mathrm{p}=0.001)$ from $17.3 \mu \mathrm{U} / \mathrm{ml}$ before hemodialysis sessions to $5.45 \mu \mathrm{U} / \mathrm{ml}$ just after the hemodialysis sessions.

c) In the subgroup II, the mean of fasting serum insulin levels significantly dropped $(\mathrm{p}=0.001)$ from $11.18 \mu \mathrm{U} / \mathrm{ml}$ before hemodialysis sessions to $3.64 \mu \mathrm{U} / \mathrm{ml}$ just after the hemodialysis sessions.

\section{HOMA IR}

In the 100 studied patients, the mean of HOMA IR levels significantly dropped $(\mathrm{p}=0.0074)$ from 3.5 before hemodialysis sessions to 1.0 just after the hemodialysis sessions (Table 2). In comparison between the two studied subgroups, in subgroup I, HOMA IR before (HD) ranged between 0.94-16.32 with mean 
value $4.58 \pm 3.37$ and in subgroup II ranged $0.58-5$ with mean value $2.37 \pm 1.16$. While in subgroup I, HOMA IR after (HD) ranged 0.713.76 with mean value $1.28 \pm 0.66$ and in subgroup II ranged 0.17 1.70 with mean value $0.70 \pm 0.37$. There was statistical significant decrease in HOMA IR just after the hemodialysis sessions in both subgroups $(\mathrm{P}<0.05)$ (Figure 1$)$. There was a negative significant correlation between HOMA IR before hemodialysis sessions and creatinine level before hemodialysis sessions ( $r=-.225, \mathrm{p}=.024)$, also there was a negative correlation between HOMA IR levels after the hemodialysis sessions and creatinine levels just after the hemodialysis sessions $(r=-.286, \mathrm{p}=.004)$.

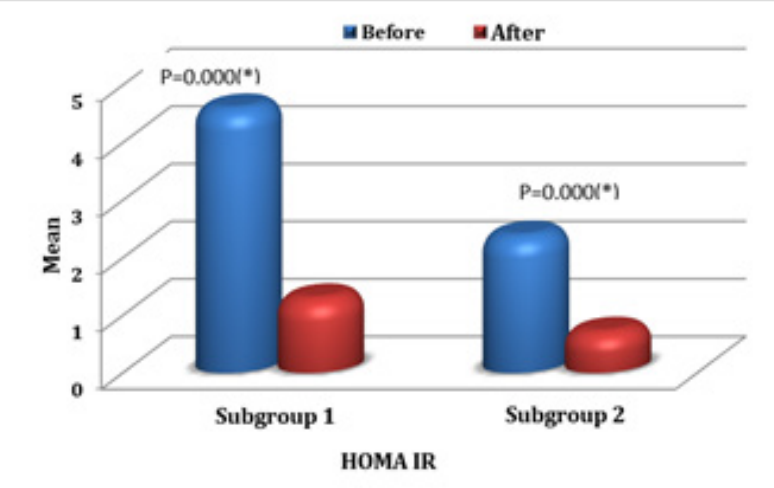

Figure 1: Comparison between the two studied subgroups regarding HOMA IR.

\section{Discussion}

Insulin resistance is a characteristic feature of ESRD. Different mechanisms are implicated in the pathogenesis of insulin resistance in ESRD including; low physical activity levels, toxins of the uremic state, metabolic acidosis, electrolyte disturbance, chronic inflammatory state, and abnormal adipokines levels leading to a post insulin-receptor defect in different insulin sensitive tissues $[14,15]$. In this present study, there was a significant decrease in fasting serum insulin levels after hemodialysis in the studied patients regardless of whether they suffer from T2DM or not; this was previously reported by Nad, et al (2014) who found that the serum insulin levels significantly decreased after hemodialysis in the diabetic and non-diabetic patients [16]. The main fining of our study was the significant improvement in IR immediately after the hemodialysis sessions even in patients without T2DM. Duncan E et al (2009) found HOMA-IR levels in the diabetic group significantly decreased after HD, but there was no significant change in levels of HOMA-IR in their non-diabetic participants [17]. Another important fining of our work is the significant negative correlation between HOMA-IR and serum creatinine levels. Similarly, Kobayashi S et al (2005) found that insulin resistance is correlated linearly with decline in renal functions [1].

\section{Conclusion}

Hemodialysis sessions may cause am immediate improvement in the insulin resistance state in patients with ESRD with or without history of T2DM; this could have some important metabolic implications on this group of patients.

\section{References}

1. Kobayashi S, Maejima S, Ikeda T, Nagase M (2000) Impact of dialysis therapy on insulin resistance in end-stage renal disease: Comparison of haemodialysis and continuous ambulatory peritoneal dialysis. Nephrol Dial Transplant 15(1): 65-70.

2. American Diabetes Association (2012) Diagnosis and classification of diabetes mellitus. Diabetes Care 35: 64-71.

3. Centers for Disease Control and Prevention (2005) Incidence of endstage renal disease among persons with diabetes-United States, 19902002. MMWR Morb Mortal Wkly Rep 54(43): 1097-1100.

4. Reaven GM (1988) Role of insulin resistance in human disease. Diabetes 37(12): 1595-1607.

5. Alvestrand A, Mujagic M, Wajngot A, Efendic S (1989) Glucose intolerance in uremic patients: The relative contributions of impaired cell function and insulin resistance. Clin Nephrol 31(4): 175-183.

6. Macaulay SL, Larkins RG (1988) Impaired insulin action in adipocytes of New Zealand obese mice: A role for post binding defects in pyruvate dehydrogenase and insulin mediator activity. Metabolism 37(10): 958965.

7. Lindner A, Charra B, Sherrard DJ, Scribner BH (1974) Accelerated atherosclerosis in prolonged maintenance hemodialysis. N Engl J Med 290(13): 697-701.

8. Ma KW, Greene EL, Raij L (1992) Cardiovascular risk factors in chronic renal failure and hemodialysis populations. Am J Kidney Dis 19(6): 505513.

9. Rowe JW, Young JB, Minaker KL, Stevens AL, Pallotta J, et al. (1981) Effect of insulin and glucose infusions on sympathetic nervous system activity in normal man. Diabetes 30(3): 219-225.

10. Shoji T, Emoto M, Nishizawa Y (2001) HOMA index to assess insulin resistance in renal failure patients. Nephron 89 (3): 348-349.

11. Matsuda M (2010) Measuring and estimating insulin resistance in clinical and research settings. Nutr Metab Cardiovasc Dis 20(2): 79-86.

12. American Diabetes Association (1998) Consensus Development Conference on Insulin Resistance. Diabetes Care 21(2): 310-314.

13. Bonora E, Targher G, Alberiche M, Bonadonna RC, Saggiani F, et al. (2000) Homeostasis model assessment in the assessment of insulin sensitivity: studies in subjects with various degrees of glucose tolerance and insulin sensitivity. Diabetes Care 23(1): 57-63.

14. Collins AJ, Foley RN, Gilbertson DT, Chen SC (2015) United States Renal Data System public health surveillance of chronic kidney disease and end-stage renal disease. Kidney Int Suppl (2011) 5(1): 2-7.

15. Ritz E, Rychlik I, Locatelli F, Halimi S (1999) End-stage renal failure in type 2 diabetes: A medical catastrophe of worldwide dimensions. Am J Kidney Dis 34(5): 795-808.

16. Nad N, P Jain, M Sharma (2014) Insulin resistance in patients of endstage renal disease (ESRD) on haemodialysis: Effect of short-term erythropoietin therapy. JIACM 15(1): 13-16.

17. Sit D, Kadiroglu AK, Yilmaz ME, Kara IH, Isikoglu B (2005) The prevalence of insulin resistance and its relationship between anemia, secondary hyperparathyroidism, inflammation, and cardiac parameters in chronic hemodialysis patients. Ren Fail 27(4): 403-407. 
(C) This work is licensed under Creative Commons Attribution 4.0 License

To Submit Your Article Click Here:

Submit Article

DOI: $10.32474 / A D 0.2019 .02 .000137$

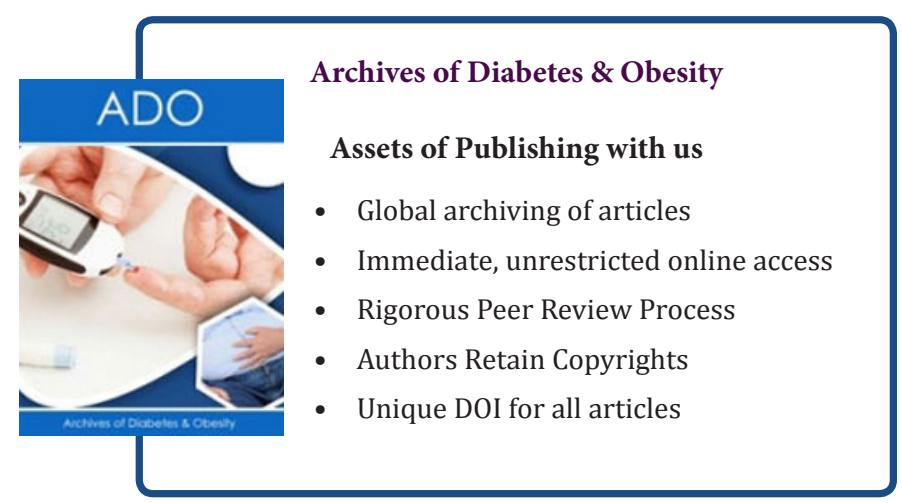

